\title{
Disposition Supplemental Qualifiers Dataset
}

National Cancer Institute

\section{Source}

National Cancer Institute. Disposition Supplemental Qualifiers Dataset. NCI Thesaurus.

Code C147203.

A dataset containing supplemental information, specifically non-standard variables, to parent records in the disposition domain. 